\title{
Emotions and Spillover Effects of Social Networks Affective Well Being
}

\author{
Eran Rubin, California State University Fresno, Craig School of Business, USA \\ Frederik Beuk, University of Akron, College of Business, USA
}

\begin{abstract}
A growing body of literature supports the notion that the well-being of individuals is influenced by their social networks site (SNS) experiences. In this research, the authors analyze the effect of such SNS experience perceptions, termed social networks affective well-being (SNAWB) on behavior in non-SNS sites. Specifically, the authors ask if the visual interface design of a non-SNS site affects the level to which the decisions made in that site are influenced by the decision maker's SNAWB. Relating to theory on emotion and action readiness, this research hypothesizes on the expected effects of a visual interface design that includes elements that may trigger SNS-related emotions. To test the hypothesis, this paper conducts two experiments: 1) an online experiment and 2) a controlled lab experiment with eye-tracking. The results show that individuals' decisions are affected by the level to which the website interface design may trigger SNS emotions. The results further provide evidence on the emotional process leading to different effects according to the type of decision made.
\end{abstract}

\section{KEYWORDS}

Affective Well-Being, Decision Making, Emotions, SNS

\section{INTRODUCTION}

The prevalence of technology-based activities in the lives of individuals is raising increasing attention on the possible effects they may have on individuals' emotions and feelings. Specifically, the ubiquitous human interaction through social network sites (SNS) is expected to affect one's subjective well-being, a construct that relates to people's evaluation of their lives. These evaluations include emotional reactions to events, moods, and judgments they form about their life satisfaction and fulfillment (Diener et al., 2003).

While the active contribution of SNS content can have positive aspects (Boughzala, 2016; Carlson et al., 2016; Verduyn et al., 2015), there is increasing evidence for the negative relationship between viewing social network sites and well-being (Krasnova et al., 2015; Labrague, 2014; Pantic et al., 2012; Shaw et al., 2015; Smith \& Kim, 2007; Tandoc et al., 2015; Verduyn et al., 2015). For example, it has been suggested that excessive use of social media sites can result in strong pathological and maladaptive psychological dependency on social media (Turel \& Serenko, 2012) and a tendency to discontinue interactions (Turel, 2015). It has also been shown that online social networks use can be 
linked with perceived loneliness (Matook et al., 2015) and that envy plays a significant role in SNS use (Krasnova et al., 2015). Overall, given the range of possible effects related to SNS, different individuals may have different emotions and feelings associated with the use of social networks (Krasnova et al., 2015). These feelings may be termed social networks affective well-being (SNAWB), and in this research, we ask how one's SNAWB affects his/her decision behavior online.

Theory related to emotion and action suggests that similarities in emotional structure may trigger similarities in action tendencies (Frijda, 1987). This means that when an arbitrary system renders its users to (subconsciously) build an emotional structure similar to that of social networks, actions in that environment may also be moderated by the user's SNAWB. This may be true even if the purpose and nature of the system or site is unrelated to social networks (which we term a non-SNS site).

Accordingly, in this research, we analyze whether the visual design of a non-SNS site may trigger SNS related emotions due to subtle visual design similarities (which we term design cues) and whether decisions made in that environment are biased and influenced by the SNAWB of the interacting users. In two experiments, we test whether similarities in visual design render SNAWB relevant in decision making, and how that emotional process takes place.

Our two experiments are designed to analyze the extent to which decision making is moderated by SNS design cues found in the non-SNS site in which the decision is made. We analyze both a decision that is primarily driven by rationality and competence (investment decision) and a decision that is more driven by affect (employment decision).

Specifically, since social network content is known to be considerably about outdoor activities and travel, that is, individuals often refer to activities (Hu et al., 2014), as well as positive portrayals of individuals (Hu et al., 2014; Krasnova et al., 2015; Lee-Won et al., 2014), the two decision sites differ in the extent to which they provide cues to positive portrayals of individuals and the outdoors as typically projected in SNS. We establish this by having the pictures of the company executive team portrayed in one site (henceforth, the SNS-triggering site) in a positive manner with an outdoor background, while the pictures of the executive team of the other site are portrayed with no SNS design cues (henceforth, the non-SNS-triggering site). Thus, the non-SNS-triggering site provides a control environment for behavior and emotion, against which we compare behavior and emotion in the SNS triggering site.

Our first experiment is an online experiment. This experiment allows for a large sample size and enables us to analyze whether the integrated design cues render SNAWB relevant in different types of decisions. That is, we analyze the mean effect of SNAWB on decision making, and possible differences in effects according to the type of decision made. Our second experiment is conducted in a controlled eye-tracking lab environment and comes to analyze the conditions for having such effects-namely, emotional structure and conditions of processing SNAWB design cues. Based on theory on emotion and action, we conjecture that the higher the exposure to SNS triggering design cues, the more they are internalized and processed, and the stronger the effect of SNAWB on the decision made. Overall, the results of both experiments support our hypothesis about the moderating effect of SNAWB on decision making in an environment with SNS-triggering design cues.

This study contributes to the understanding of the relationship between emotions and technologybased user behavior. Previous research associated with emotions and technology has focused on emotions when using social network sites (Cheikh-Ammar \& Barki, 2013; Koch et al., 2012), communication of emotions (Wang et al., 2004), and the role of emotions in technology adoption (Beaudry \& Pinsonneault, 2010; Partala \& Saari, 2015). The current study adds to this line of research by enhancing our understanding of the role of emotional spillovers across different online environments. That is, we analyze how emotion-effects may propagate from one site to another and how this propagation of emotion affects decision making.

This study also contributes to the growing literature on the dark side of technology. Indeed, typically the information systems (IS) literature studies positive aspects of technology, and deficiencies are less often highlighted. For example, it has been noted that with effective interface design user 
satisfaction can be enhanced (e.g., Hsieh et al., 2012), knowledge creation can be supported (e.g., Khodakarami \& Chan, 2014), and engagement can be facilitated (e.g., Kim et al., 2013). However, technological innovations can come at a cost. While different interface designs come to facilitate enjoyment and ease of use, they can result in "bad habits" and addiction (Turel \& Serenko, 2012). While online reviews are often thought to empower users, they may instead reshape preferences (Liu \& Karahanna, 2017). Rather than improve communication in a workplace, work-related instant messaging technology can negatively affect task performance due to interruptions (Gupta et al., 2013). Our study relates to possible decision biases stemming from experience in SNS. We show that also here, potential positive outcomes of technology may be reduced due to spillover of negative effects of SNAWB.

The rest of this paper continues as follows. Section 2 provides a literature review. Sections 3 and 4 describe our two experiments, their analyses, and the results. Section 5 concludes with a summary and discussion.

\section{RELATED LITERATURE}

For almost two decades, social media penetrates almost every aspect of our lives, from the way we learn (Haythornthwaite, 2005; Paul et al., 2012), work with our colleagues (Ollier-Malaterre et al., 2013), consume products (Goh et al., 2013; Hajli, 2014), obtain information (Bond et al., 2012), vote (Spierings \& Jacobs, 2014) and interact (Papacharissi, 2010; Jiang et al., 2013). As such, whether we are aware of it or not, our exposure to social networks affects the perception we develop regarding the quality of our lives, i.e., subjective well-being (Argyle, 2013; Diener et al., 2003).

Subjective well-being is composed of rational responses to events, as well as emotional, affective, experiences and sentiments (Diener et al., 2003). When considering the effect of social networks on subjective well-being, the latter, emotional responses, are especially relevant, as social networks have been shown to have unique emotional effects (Krasnova et al. 2015; Lee et al., 2013; Smith \& Kim, 2007). Further, much of the content shared and consumed online is based on emotional sentiments (Brady et al., 2017; Chmiel et al., 2011; Coviello et al., 2014; Stieglitz \& Dang-Xuan, 2013; Jin et al., 2017), stressing the potential of social networks to affect the emotional contributors to subjective well-being., i.e., SNAWB. Indeed, it has been suggested that excessive use of social media sites can result in strong pathological and maladaptive psychological dependency on social media (Turel \& Serenko, 2012), and a tendency to discontinue interactions (Turel, 2015). It has also been shown that online social networks use can be linked with perceived loneliness (Matook et al., 2015), and that envy plays a significant role in reducing the cognitive and affective well-being of a user (Krasnova et al., 2015).

While the relationship between social networks and subjective well-being has recently gained increasing attention, the possible online behavioral aspects, outside SNS, that stem from perceptions of social network experiences, have been largely unexplored. This is unfortunate since it is highly conceivable that feelings associated with social networks experience would affect behaviors in other online contexts.

More specifically, one's interaction with social networks would be associated with different memories and images, which may be recalled in other, non-SNS, online contexts through visual design. In turn, when SNS memories and images come to a person's mind in other contexts, they make for emotional triggering events, or internal events of emotion elicitation (Scherer, 2005). That is, such recalled or imagined representations are facilitators of emotions (Ekman, 1994; Frijda, 2017; Scherer, 2004, 2005). In this context, one of the primary properties of social networks is their high use of photographs and videos (Rainie et al., 2012). For example, Snapchat experiences about 400 million snaps a day, with around 9,000 photos being shared every second (Lister, 2018). Notably, photos posted in social networks predominantly include positively self-posed pictures of a single person and are associated with outdoor activities in various locations (Hu et al., 2014; Krasnova et 
al., 2015; Lee-Won et al., 2014). When the design of a non-SNS site incorporates such images, that site is expected to facilitate similar emotion elicitation, even if the online setting is not of an SNS.

Importantly, it is well agreed in theoretical frameworks that emotions involve states of action readiness (e.g., Ellsworth \& Scherer, 2003; Frijda, 2017; Scherer, 2005; Strack \& Deutsch, 2004). Arnold (1960) defines emotion as "felt action tendency." Frijda (1986, p.71) further defines emotion as "the readiness (or unreadiness) to enter into contact or interaction with some object, and the mode of that contact or interaction. ... Emotions are tendencies to establish, maintain, or disrupt a relationship with the environment." These definitions have been proven to have much validity both in empirical studies (Frijda et al., 1989; Hardy, 2006; Roseman et al., 1994) and natural observations (e.g., SheetsJohnstone, 1999; Susskind et al., 2008). For example, in empirical experiments, individuals identify emotions they have with action tendencies (Roseman et al., 1994); and neurological observations show that the facial expressions associated with emotions do not merely come to support communication, but rather are related to changes in action readiness (Susskind et al., 2008).

The relevance of emotions for actions has been recognized in IS research, mostly in the context of technology adoption. In this context, Straub (2009) has noted that there is a need for a more empirical basis for understanding the influence of emotions on the technology adoption process. The research on emotion-related constructs in technology adoption is mostly limited to such constructs as enjoyment and anxiety as deriving perceptions on ease of use (Venkatesh \& Bala, 2008), rather than a more general emotional structure indicating action readiness. Further, these studies have looked at emotions within the context of a single system's use.

Related to this, while studies on IS and emotions were typically studied within the context of a single system, the theory above suggests their relevance across systems. Indeed, Partala and Saari (2015) show evidence that emotions experienced in "the most influential adoption events," affect adoption tendencies of other systems. This further lends support to the notion that similarities in design between an arbitrary website and SNS may trigger emotions that are similar, yielding similarities in decision actions. We hypothesize and test for such effects in two experimental studies, which we discuss next.

\section{EXPERIMENTAL STUDY 1}

In our first study, we analyze the relationship between SNAWB and the action readiness associated with a non-SNS site. Our main hypothesis is that the readiness of a decision-maker to take action in a non-SNS site is moderated by the interaction of the decision-maker's SNAWB and the level to which the site design has SNS emotion triggering design cues.

\section{Hypotheses Development}

Social networks have dual effects on one's well-being. On the one hand, people rationally engage with social media and appreciate its ability to fulfill their social needs (Malik et al., 2016; Sheldon \& Bryant, 2016; Whiting \& Williams, 2013). Specifically, individuals find social media useful in overcoming boredom and passing idle time, enabling social interactions, providing entertainment, and facilitating free expression (Whiting \& Williams, 2013). On the other hand, the consumption of such media is associated with loneliness, excessive consumption of media, and the surveillance of others (Sheldon \& Bryant, 2016; Whiting \& Williams, 2013), acts which are linked to negative effects (Appel et al., 2016; Kross et al., 2013; Steers et al., 2014; Tandoc et al., 2015; Verduyn et al., 2015).

The less positive aspects of SNS experiences are most pronounced when considering one of SNS's most dominant features, namely, their facilitation of the extensive use of photos. Such photos are typically positively posed in various backgrounds, but the unique emotional-oriented experience in social networks renders these typically positive aspects of happiness, optimism, and fun also as a source for negative emotional outcomes (Krasnova et al., 2015). That is, while positive expressions of 
individuals are typically contagious upon the observing individual, the effects may be less pronounced and even detrimental in the case of SNS.

More specifically, outside the SNS realm, research on emotional contagion has shown that exposure to an individual expressing positive emotions would produce a corresponding change in the emotional state of the observer. It has specifically been found that exposure to images of an individual smiling or frowning produced congruent changes in subjects' own facial expressions as well as physiological and self-reported measures of emotion, a process termed primitive emotional contagion (Hatfield et al., 1994; McHugo et al., 1985). In agreement with this, it has been shown that people sometimes deliberately show positive emotional displays to receive favorable social feedback (Pugh, 2001). For example, service employees often show positive emotional expressions in order to enhance consumers' consumption experiences (Barger \& Grandey, 2006). Furthermore, people who express smiles are often perceived highly in many dimensions, such as kindness, sociability, pleasantness (Mueser et al., 1984), and politeness (Bugental, 1986).

Accordingly, our first hypothesis on the effect of positively posed photos in a non-SNS site is regarding the emergence of positive attitudes by the interacting individuals:

H1: A non-SNS website incorporating positively posed photos will enhance the propensity for engagement with the entity represented by the website.

Related to this, the positive contagious effect happens through subconscious imitation (Hatfield et al., 1994; Pugh, 2001; Tsai \& Huang, 2002). In fact, the process is noted as "primitive emotional contagion," and defined as an individual's tendency to "mimic and synchronize facial expressions, vocalizations, postures, and movements with those of another person and, consequently, to converge emotionally" (Hatfield et al., 1994, p.5). Indeed, Sutton (1991) showed that bill collectors expressed an emotion of urgency through their vocal tones to make debtors feel anxious and consequently pay off their debts. Similarly, Pugh (2001) showed that when bank tellers smile more and increase eye contact, the customers exhibit similar behaviors. Accordingly, due to the contagious effect of a positive display of attitude, we expect that a positive display of individuals in a website's pictures would have positive effects across different decisions:

H2: A non-SNS website incorporating positively posed photos will enhance the propensity for engagement with the entity represented by the website, regardless of the nature of the engagement considered.

While positively posed pictures are expected to have the noted positive contagion effect, SNS emotional perceptions may moderate this effect. Namely, there is substantial evidence for a negative effect of SNS use on affective well-being (e.g., Kross et al., 2013), giving rise to feelings of depression and loneliness (e.g., Selfhout, 2009). Since one of the core aspects of SNS is positive self-portrayal in pictures and posts (e.g., Appel et al., 2016; Qiu et al., 2012), exposure to such positively posed photos in other websites may trigger some of the emotions associated with SNS use. The less positive the perceived SNS experience one has, the less positive will the effect of the positively posed picture would be. We thus hypothesize the following:

H3: SNAWB moderates the positive effects of positively posed photos on the propensity of the interacting individuals for engagement with the entities represented by the website.

While contagion through emotional expression happens through subconscious imitation (Hatfield et al., 1994; Pugh, 2001; Tsai \& Huang, 2002), emotions triggered through memory require some processing of their relevance to the action at hand. Experiences or events are emotionally relevant 
when they appear to favor or harm the individual's goals, and emotions are expected to play a central role when it comes to actions taken towards fulfilling goals (Frijda, 2017). Such emotional processes are similar to processes of familiarity and recollection (Hajcak et al., 2012; Rugg \& Curran, 2007; Yonelinas, 2001), which are evident in psychology (Philippot et al., 2003; Watkins et al., 2008) and pervasive in neurological studies (e.g., Aggleton et al., 2005).

Hence, further related to the moderating effect of SNAWB, we look at the level to which SNS related emotions may be processed as relevant for the engagement decision. An engagement can differ along the two dimensions of affect and competence (Judd et al., 2005; Ybarra et al., 2001). The more affective the expected engagement, the more the SNS related triggering emotions are relevant. That is, some engagements may entail affective consequences more than others, and the more affective the expected consequences of an engagement, the more relevant the SNS related emotions would be.

Under this framework, the affect dimension is more relevant in a work environment setting, while the competence dimension is more relevant in an investment setting. While both workplace engagements and investment engagements include both competence and affective dimensions, workplace engagements can be considered more prone to affect consequences than investment engagements. A work environment has many emotional consequences on the individual as the identity of the individual interacts on a daily basis with the identity of the organization he or she works at (Ashforth et al., 2008). Indeed, emotions have been shown to affect career choices (Farnia et al., 2018).

In the workplace, positive and negative affective events have been found to be directly related to intentions to leave or stay (Grandey et al., 2002). For example, by sampling employee job satisfaction ratings on a daily basis, Dimotakis, Scott, and Koopman (2011) show that workplace interpersonal interaction characteristics are highly associated with job satisfaction. Rosin and Korabik (1991) show that female managers identify office politics and a socially male-dominated environment as a core determinant of job satisfaction. It has further been shown that workplace-related events can lead to emotional exhaustion and various detrimental consequences stemming from it (Cropanzano et al., 2003; Goel \& Thakor, 2005). In contrast to this, while investment decisions incorporate an affective dimension (e.g., Epstein \& Freedman, 1994; Shepherd et al., 2009; Xie et al., 2005), they are more highly associated with the competence dimension (Farraghe et al., 1994; Marino, 1996). Namely, an investor's engagement with a company is mostly related to the following of relevant information. As such, while not irrelevant, affective-related information takes a secondary role. Such affective information includes corporate responsibility, customer care, and employee treatment (Epstein \& Freedman, 1994; Hockerts \& Moir, 2004). ${ }^{1}$ Competence related performance information, on the other hand, is core in company investor relationships (Bushee \& Miller, 2012; Farraghe et al., 1994).

Since investment engagements are primarily associated with the competence dimension while employment engagements are primarily associated with the affective dimension we hypothesize:

H4: The moderating role of SNAWB is more pronounced in the propensity to work for than propensity to invest in the entity represented by the website.

\section{Methodology}

We conduct an online experiment in which we ask users to make engagement decisions in two very similar online sites that differ only in the level to which their visual design is expected to trigger SNS emotions. Namely, the sites differed in the level to which the photographs are positively posed in various environments, which, as noted, is a dominant aspect of social networks (Hu et al., 2014; Krasnova et al., 2015; Lister, 2018; Rainie et al., 2012). For example, compare Figure 1 and Figure 2.

Participants were United States-based Amazon's Mechanical Turk workers. We opted for "master" workers, as they are considered by Amazon to be more reliable. Each subject was presented with two web pages pertaining to the executive teams of the two companies. Immediately after viewing 
Figure 1. Example of company page designed to trigger SNS related emotions

\begin{abstract}
About ProSpect
ProSpect is a startup company with 30 employees that specializes in using AI and Analytics in order to provide advance marketing solutions to small and medium enterprises. Our solutions tap on social media data and cross reference analytics pertaining to a wide range of online companies and individual customer behavior on the web,
\end{abstract}

Our Team

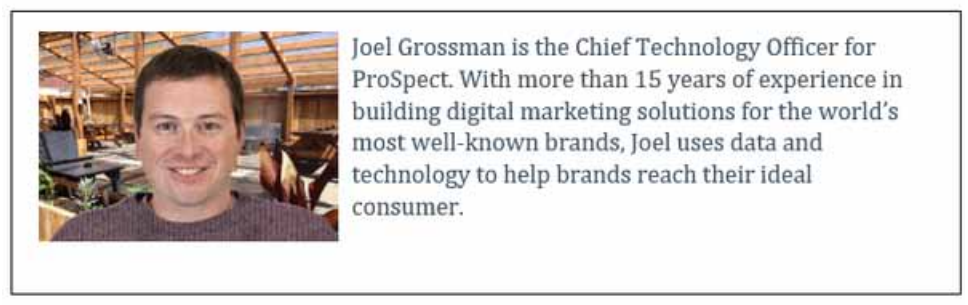

Michael Glefke is ProSpect's Managing Director. Michael oversees business operations and client services for ProSpect offices. Most recently, Michael served as VP, Group Account Director. Prior to joining ProSpect in 2016, he ran sales and client services at Ethology. A digital marketing industry veteran, he has over 10 years of experience working with leading brands in driving their business forward.
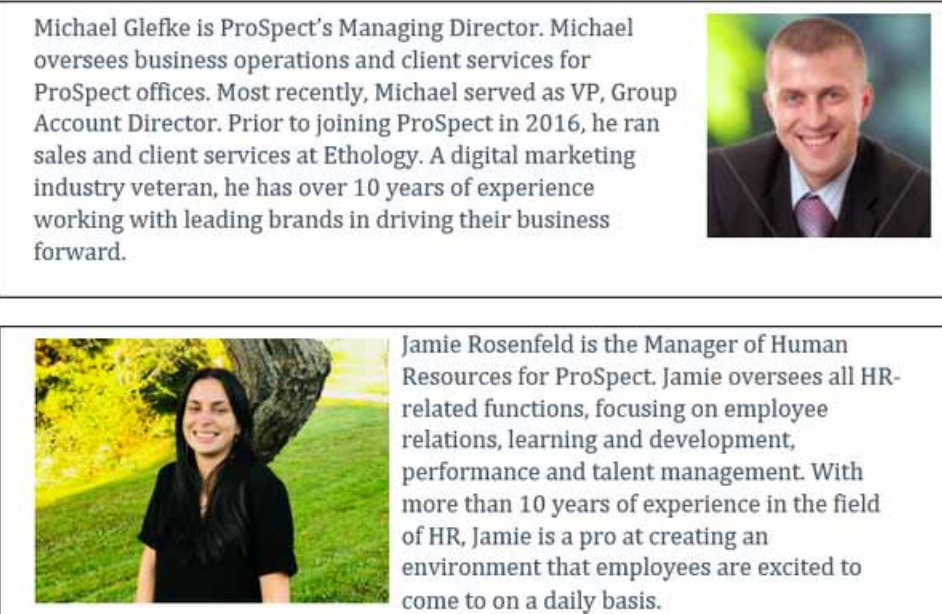

Jamie Rosenfeld is the Manager of Human

Resources for ProSpect. Jamie oversees all HRrelated functions, focusing on employee relations, learning and development, performance and talent management. With more than 10 years of experience in the field of HR, Jamie is a pro at creating an environment that employees are excited to come to on a daily basis.

each site, subjects were asked to decide on their propensity to engage with the company associated with that site further. The order of the companies was counterbalanced across subjects. Decisions were made along the two dimensions of affective and competence engagements, using measures of propensity to work for and propensity to invest in the company, respectively.

Finally, following their assessment of the companies, subjects were asked to indicate their level of SNAWB, with a scale based on Krasnova et al. (2015). Subjects also reported their general tendency to feel envy (Cohen-Charash, 2009), with a dispositional envy scale based on Smith et al. (1999). All items loaded as expected and showed both discriminant and internal validity (reported in Table 6 of the Appendix).

To rule out any bias related to the perception of team members in terms of their appearance and description, the photos' backgrounds and the postures of the team members were counterbalanced between subjects. ${ }^{2}$ That is, the team members that were part of the SNS-triggering site for one subject would be part of the non-SNS-triggering site for another. An example of such counterbalanced information pages is depicted in Figure 3 of the Appendix. In total, our balanced sample includes 184 subjects. 
Figure 2. Example of company webpage designed not to trigger SNS emotions

\section{About 360Pro}

360Pro is a startup company with 32 employees that specializes in Data

Analytics and Artificial Intelligence based advanced marketing solutions to businesses. The company's solution are based on online business data and social media data to learn on customer behavior and marketing opportunities,

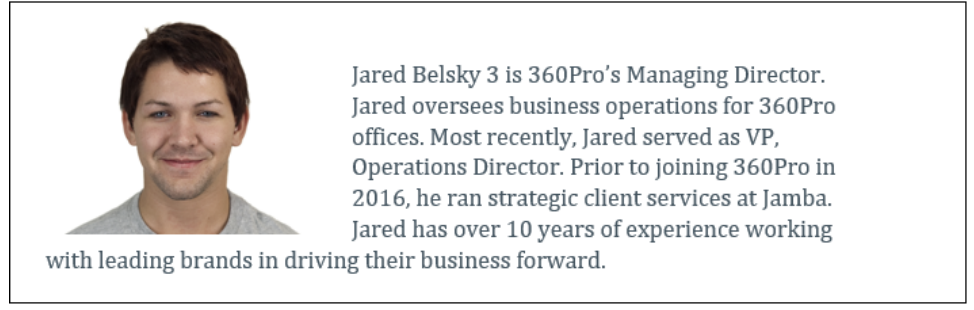

Thomas Meisner is the Chief Technology Officer for 360Pro. With more than 15 years of experience in building digital marketing solutions for the world's most well-known brands, Thomas uses data and technology to help brands reach their ideal consumer.
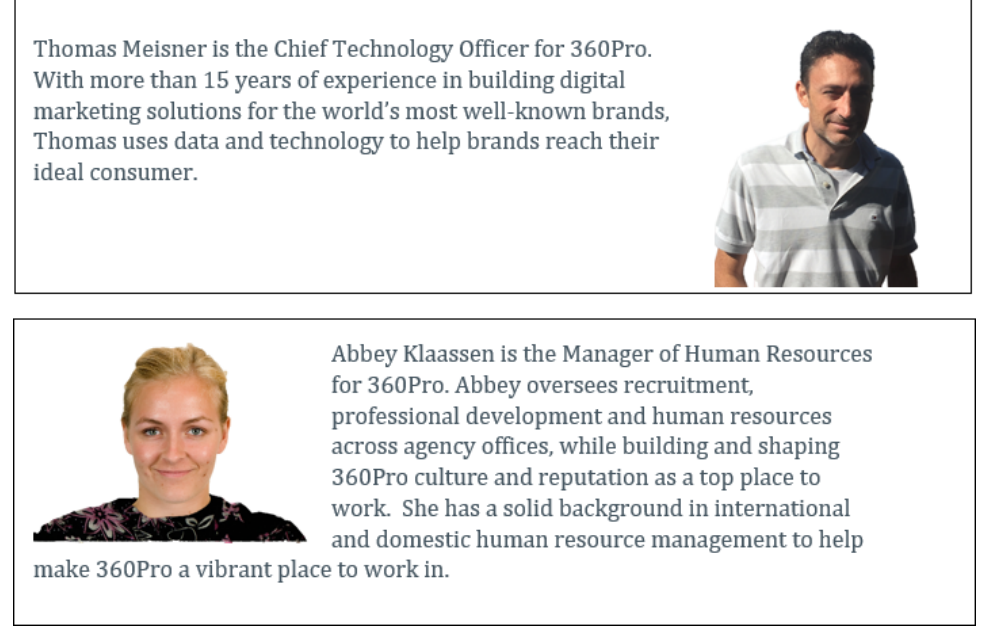

\section{Results}

We begin by analyzing the effects of team members expressing more positive facial emotions compared to more neutral ones. Table 1 provides the results of ANOVA tests pertaining to the difference between intention to work for (invest in) a company with more positive expressions vs. less positive expressions, when each company is evaluated independently.

Table 1. Difference between intention to work for (first row) and invest in (second row) a company with more positive expressions vs. less positive expressions

\begin{tabular}{|l|l|l|l|l|l|}
\hline \multicolumn{1}{|c|}{ Variable } & \multicolumn{1}{c|}{ N } & \multicolumn{1}{c|}{ Mean } & \multicolumn{1}{c|}{ Std. Dev } & Sig. & t stat \\
\hline $\begin{array}{l}\text { (1) Difference "work for" for individuals with } \\
\text { positive emotions vs less positive emotions }\end{array}$ & 184 & 0.33 & 1.12 & 0.0001 & 3.97 \\
\hline $\begin{array}{l}\text { (2) Difference "invest in" for individuals with } \\
\text { positive emotions vs less positive emotions }\end{array}$ & 184 & 0.27 & 1.17 & 0.002 & 3.14 \\
\hline Difference (1-2) & 184 & 0.05 & 0.86 & 0.37 & 0.89 \\
\hline
\end{tabular}


Consistent with $\mathrm{H} 1$, the tests clearly show that individuals are more inclined to work with and invest in a company when its executive team members exhibit a more positive emotional expression. The results are significant at the 0.01 level in both cases, suggesting a process of emotional contagion. As for our $\mathrm{H} 2$ hypothesis, that the positive contagion effect would be similar across different decisions, we find supporting results as well. While the mean contagion effect on the working decision is slightly higher than on the investment decision, the difference in engagement propensity across the two decision types is insignificant $(\mathrm{t}=0.89, p<0.37)$.

We next turn to $\mathrm{H} 3$ and $\mathrm{H} 4$ and test the moderating effect of the SNAWB of the individual making the decision on the two types of engagements. In these regressions, we include the dispositional envy and the age of the respondents as control variables. The dependent variable in these estimations is the difference between the two sites in the propensity to work for the company (Table 2) and to invest in the company (Table 3).

The results depicted in both tables support hypothesis $\mathrm{H} 3$ on the moderating effect of SNAWB. SNAWB is significant at the $5 \%$ level across all estimation models, which supports the notion that one's SNAWB affects engagement decisions in non-SNS sites when such sites include SNS-emotion triggering elements.

However, the results do not support H4. While we have hypothesized that SNAWB would be more relevant for the work-related decision than the investment-related decision, Chi-square tests for

Table 2. OLS estimations of difference in the propensity to work for a company based on emotional expressions on the site

\begin{tabular}{|l|l|l|l|l|}
\hline \multicolumn{1}{|c|}{ Work diff. } & \multicolumn{1}{c|}{$(\mathbf{1})$} & \multicolumn{1}{c|}{ (2) } & \multicolumn{1}{c|}{ (3) } & \multicolumn{1}{c|}{ (4) } \\
\hline SNAWB & $0.16^{*}$ & $0.17^{*}$ & $0.17^{*}$ & $0.17^{*}$ \\
\hline & $(0.08)$ & $(0.08)$ & $(0.07)$ & $(0.08)$ \\
\hline Age & -0.004 & & -0.005 & \\
\hline & $(0.01)$ & & $(0.01)$ & \\
\hline Dispositional envy & -0.01 & -0.01 & & \\
\hline & $(0.06)$ & $(0.06)$ & & \\
\hline$N$ & 184 & 184 & 184 & 184 \\
\hline$R^{2}$ & 0.09 & 0.09 & 0.09 & 0.09 \\
\hline
\end{tabular}

Standard deviations are in parenthesis. ${ }^{*}$ indicates significance at $5 \%$.

Table 3. OLS estimation of the difference in the propensity to invest in a company based on emotional expressions displayed on the site

\begin{tabular}{|c|c|c|c|c|}
\hline Invest. diff. & (1) & (2) & (3) & (4) \\
\hline \multirow[t]{2}{*}{ SNAWB } & $0.19^{*}$ & $0.20 *$ & $0.18^{*}$ & $0.18^{*}$ \\
\hline & $(0.09)$ & $(0.09)$ & $(0.08)$ & $(0.08)$ \\
\hline \multirow[t]{2}{*}{ Age } & -0.007 & & -0.007 & \\
\hline & $(0.01)$ & & $(0.01)$ & \\
\hline \multirow[t]{2}{*}{ Dispositional envy } & 0.05 & -0.05 & & \\
\hline & $(0.06)$ & $(0.06)$ & & \\
\hline$N$ & 184 & 184 & 184 & 184 \\
\hline$R^{2}$ & 0.03 & 0.03 & 0.03 & 0.03 \\
\hline
\end{tabular}

Standard errors are in parenthesis. * indicates significance at $5 \%$. 
the difference of coefficient across the decision types are insignificant. We investigate this further in Study 2.

Overall, the results support the notion that SNAWB is relevant in decision making in online environments that include SNS emotion triggering visual design. When a website's design includes visual cues that may trigger SNS emotions, the actions in that website will be moderated by the interacting person's SNAWB. While this experiment has provided evidence for the relevance of SNAWB according to the level to which SNS design cues are present, we have not related to the emotional process that takes place. In our next experiment, we further analyze the emotional process when visiting an SNS emotion-triggering site.

\section{EXPERIMENTAL STUDY 2}

In our second study, we seek evidence for the similarities in one's emotional structure after interacting with an SNS and after visiting a website with an SNS emotion triggering design. We further analyze the relationship between the level to which one processes the SNS emotion triggering design and the relevance of the established emotional structure for decision outcome.

\section{Hypotheses Development}

We extend our analysis regarding the incorporation of the triggered SNS emotion in decision making by investigating the formed emotional structure and the processing of emotions.

Emotional structure can be defined through the relevance of individual emotion-related words to one's state (Frijda, 1987), and this emotional structure amounts to action readiness. More specifically, Frijda (1987) provided a set of 36 words related to emotion and has shown that the same emotionrelated word is associated with similar action tendencies by different individuals. Accordingly, a person's emotional structure and overall action readiness can be quantified based on the level to which that person identifies with each of those 36 words. Examples of these emotional words are: attentive, indignant, anxious, restless, neutral, suspicious, relaxed, energetic, and serious.

Emotions relate to one's experience from events. In the context of our research, this is the event of viewing a webpage with a certain design. If emotions triggered by SNS design cues are responsible for one's decision outcome, her emotional structure is expected to be similar to the emotion structure she forms upon an SNS experience. Accordingly, our first hypothesis is that the emotional structure following the act of viewing a webpage with an SNS triggering design is similar to the emotional structure following the act of viewing an actual SNS:

H1: An individual viewing a non-SNS website incorporating SNS design cues would have an emotional structure that is similar to the emotional structure that an individual has when viewing an SNS site.

In his comprehensive review of emotions, Frijda (1986) notes that action tendencies and emotions are equivalent. More specifically, "emotions are modes of relational action readiness either in the form of tendencies to establish, maintain, or disrupt a relationship with the environment or in the form of model of relational readiness as such" (Frijda, 1986, p. 71). Given the negative aspects associated with viewing SNS content (e.g., Krasnova et al., 2015; Smith \& Kim, 2007; Verduyn et al., 2015), the more similar the emotional structure established in a site to that established in an SNS site, the lower the propensity for engagement with entities represented by that site.

H2: The more similar the emotional structure established in the site to that established in an SNS site, the lower the propensity for engagement with entities represented by the site. 
To this end, much of emotional behavior is intentional rather than only brief and sudden (Frijda 1986, p. 98). Contrary to moods that appear and persist in the absence of obvious stimuli (Ekman, 1994), emotions can be defined as short-term affective responses to appraisals of particular stimuli, situations, or events having reinforcing potential (Matthews et al., 1998; Rolls, 1999). That is, emotions' effect on the action is contingent on what is termed intentional structures, which are motivated by signals processing (Frijda, 1986; Frijda, 2017).

For example, in some cases, a person may ignore stimuli and not change action readiness based on the stimulus; in other cases, the change in action readiness may be fully materialized (LeDoux, 2003). Overall, emotional response involves some level of cognition (Frijda, 2017; Lazarus, 1982). Rather than only brief and sudden emotions extend to intentions involving processing. The important role of these intentional cognitive structures is most obvious when considering complex (i.e., nonprimitive) emotions (Frijda, 1986), such as those related to SNS. As opposed to primitive emotions, such as fear, the emotions triggered by SNS would not be sudden nor result in an instantaneous change. They are expected to be more complex and followed by some level of processing and yield an intentional structure. In the SNS environment, the emotion associated with envy, for example, may lead to an intentional structure to refrain from visiting the SNS, based on some level of processing rather than due to pure impulse. Correspondently, similarities in emotional structure may yield similarities in intentional structure, subject to the emotions being processed as relevant for the goals of the user in that site.

Accordingly, we hypothesize that one's propensity to engage with entities represented in a website is moderated by the interaction of one's processing of the SNS emotion triggered as relevant, and the level to which the emotion triggered is similar to that experienced in an SNS site:

H3: The more the emotional structure established following the viewing of a non-SNS site is similar to the emotional structure of an SNS site, the more the processing is relevant to establish differences in decision outcome.

Related to the above, emotions are appraised for their relevance. That is, while emotions are triggered by an event would yield changes in action readiness, the change may not be equally materialized as the emotions are not equally relevant for any action. Through a cognitive process, as noted, an individual may find emotions relevant and change action accordingly, or, in contrast, may find the emotions irrelevant and suppress them (Lazarus, 1982).

Seeking support to the notion that the effect of SNS design cues is different across decision types, we extend our analysis and hypothesize in this study with respect to when such differences may emerge. Namely, in Study 1, we have not analyzed the extent to which similarity of emotional structure and the processing of emotions leads to differences in decision outcomes. In this study, we seek to learn if accounting for these aspects can help identify differences in decision outcomes according to decision type. Specifically, as previously noted, SNS are expected to support affective relations more than competence relations. Therefore, the similarity in emotional structure to an SNS site and the processing of the triggered emotions is expected to be more relevant for affect-related engagement decisions than to competence related engagement decisions. Since the affect dimension is more relevant in a work environment setting (Cropanzano et al., 2003; Dimotakis et al., 2011; Goel \& Thakor, 2005), while the competence dimension is more relevant in an investment setting (Bushee \& Miller, 2012; Farraghe et al., 1994; Marino, 1996), we expect the similarity of in emotional structure to that of an SNS, and the processing of the triggered emotions to yield a stronger behavioral response in work-related decisions than in investment-related decisions. We therefore hypothesize:

H4: Emotional-structure similarities between a website and SNS, and the processing of these emotions, impacts work-related decisions more than investment-related decisions. 


\section{Methodology}

We conduct an eye-tracking experiment to observe the level to which 16 subjects (62\% male, age between 23 and 48, all US-based) view and process the SNS emotion triggering design elements.

In the beginning of the experiment, subjects are asked to view their Facebook feeds for 3 minutes and then rate the level to which each of the 36 emotion-related words currently (at time of answering) applies to them. We then confront users with action decisions with respect to the sites of Study 1, which differ only in the level to which they are expected to trigger SNS-related emotions. Following the exposure to each of the two sites, we repeated the same emotion-related word questions.

We compare the answers to the emotion-related words following the viewing of Facebook and following the viewing of a stimulus site to assess the level of similarity in emotional structure experienced by the subject when viewing the site and when viewing an SNS. ${ }^{3}$ Finally, the eye-tracking device was constantly recording the areas on the screen that the subjects were looking at. This enabled us to analyze the extent to which each subject gazed at the SNS emotion-triggering element of images with similar properties to those typically found in SNS.

\section{Results}

We begin by analyzing the emotional structure following an SNS viewing event and following each of the events of viewing the individual sites, i.e., following the viewing of an SNS-emotion-triggering site and a non-SNS-emotion-triggering site. Table 4 provides the t-test results of a difference in means between the two sites, regarding the level to which they differ in emotional structure from the emotional structure when visiting Facebook. Consistent with hypothesis H1, we see that the difference between the emotional structure following Facebook is more similar to the emotional structure following an SNS-emotion triggering site than to the emotional structure following a nonSNS-emotion triggering site.

We next analyze the effects of the SNS-triggering elements in the emotional cognition process. We consider the emotional structure established and the cognitive processing of the emotions. For this purpose, we utilize the eye-tracking data to obtain a measure of the level to which each individual has gazed at and processed the emotion-triggering elements (i.e., the photos) in the two sites. We devise two such measures, one based on the average time the individual has spent viewing the photos in the sites (AvgFixation), and the other based on the amount of time spent on viewing the first photo in the sites (FirstFixation).

We estimate the following regression model with fixed effects for company ordering:

$$
\text { DecisionDiff }_{i}=\alpha_{0}+\beta_{0} \text { EmoDiff }_{i}+\beta_{1} \text { GazeTriggers }_{i}+\beta_{2} \text { Interaction }_{i}+\varepsilon_{i}
$$

Table 4. Differences emotional structure after viewing Facebook and after viewing an SNS emotion triggering site (first row) and after viewing Facebook and a non-SNS emotion triggering site (second row)

\begin{tabular}{|l|l|l|l|l|l|}
\hline \multicolumn{1}{|c|}{ Variable } & \multicolumn{1}{|c|}{ N } & \multicolumn{1}{c|}{ Mean } & Std. Dev. & Sig. & t stat \\
\hline $\begin{array}{l}\text { (1) Difference in emotional structure } \\
\text { between SNS triggering site and FB }\end{array}$ & 16 & 2.32 & 0.88 & & \\
\hline $\begin{array}{l}\text { (2) Difference in emotional structure } \\
\text { between non-SNS-triggering site and FB }\end{array}$ & 16 & 2.67 & 0.93 & & \\
\hline Difference (1-2) & 16 & -0.34 & 0.63 & 0.04 & $-2.18^{*}$ \\
\hline
\end{tabular}

${ }^{*}$ indicates significance at $5 \%$. 
where DecisionDiff $f_{i}$ is the difference in decision outcome of individual $i$ following the viewing of an SNS-emotion-triggering site compared to a non-SNS-emotion-triggering site. Namely, (propensity for engagement decision following viewing the SNS-emotion-triggering site minus propensity for engagement decision following viewing the non-SNS-emotion-triggering site) EmotionalDifference ${ }_{i}$ is the difference in emotional structure difference (compared to SNS emotional structure) between the two sites, as experienced by individual $i$. GazeTriggers ${ }_{i}$ is the level to which the individual has gazed at and processed the emotion-triggering design elements in the two sites (i.e., either AvgFixation or FirstFixation). Finally, Interaction $n_{i}$ is the interaction effect of processing the emotions and the emotional structure difference, i.e.:

\section{Interaction $_{i}=$ Emotional Difference $_{i}$ GazeTriggers $_{i}$}

The results of the estimations are presented in Table 5. Estimations 1 and 2 are with respect to differences in work decisions. Estimation 3 and 4 are with respect to differences in investment decisions. In estimations 1 and 3, the processing of emotion-triggering elements is measured using AvgFixation, and in estimations 2 and 4 using FirstFixation.

The results broadly support the hypotheses made. Beginning with the affective, i.e., work-related, decisions. With respect to H2, Emotional Difference is significant at the 0.05 level $(p=0.05)$ and at the 0.1 level $(p=0.06)$ in Estimations 1 and 2 respectively. That is, the more similar the emotional structure established in the SNS-emotion-triggering site to that established in an SNS site, the lower the propensity to respond positively in the work-related decision. With respect to $\mathrm{H} 3$, the Interaction variable is significant at the 0.01 level in both Estimations 1 and 2 . That is, we find that the more the emotional structure of the SNS triggering site is similar to that of an SNS site, the processing of the raised emotions is relevant for the negative results to emerge, and this result is significant at the 0.01 level in both Estimations 1 and 2.

Table 5. OLS estimation of the difference in the propensity to work for a company (specifications 1 and 2 ) and invest in a company (specifications 3 and 4) based on emotional expressions displayed on the site

\begin{tabular}{|l|l|l|l|l|}
\hline & \multicolumn{1}{|c|}{$\begin{array}{c}\text { Work diff. } \\
(\mathbf{1})\end{array}$} & \multicolumn{1}{|c|}{$\begin{array}{c}\text { Work diff. } \\
(\mathbf{2})\end{array}$} & \multicolumn{1}{|c|}{$\begin{array}{c}\text { Invest. diff. } \\
\mathbf{( 3 )}\end{array}$} & \multicolumn{1}{|c|}{$\begin{array}{c}\text { Invest. diff. } \\
\mathbf{( 4 )}\end{array}$} \\
\hline & $1.66^{*}$ & $1.62^{\wedge}$ & -0.14 & -0.56 \\
\hline & $(0.76)$ & $(0.80)$ & $(1.25)$ & $(1.18)$ \\
\hline GazeTriggers (AvgFixation) & -0.0011 & & -0.0003 & \\
\hline & $(0.0008)$ & & $(0.001)$ & \\
\hline GazeTriggers (FirstFixation) & & -0.0008 & & -0.0004 \\
\hline & & $(0.0007)$ & & $(0.001)$ \\
\hline & $-0.01^{* *}$ & $-0.008^{* *}$ & 0.003 & 0.004 \\
\hline$N$ & $(0.0027)$ & $(0.0026)$ & $(0.0045)$ & $(0.0038)$ \\
\hline$R^{2}$ & 16 & 16 & 16 & 16 \\
\hline
\end{tabular}

Note: Standard errors are in parenthesis. ${ }^{\wedge},{ }^{*}$, and ${ }^{* *}$ indicate significance at the $10 \%, 5 \%$, and $1 \%$ level, respectively. 
Estimations 3 and 4 are relevant for testing Hypothesis 4, that SNS triggered emotions would affect work decisions more than investment decisions. The insignificant coefficients in both estimations related to investment decisions, i.e., Estimations 3 and 4, support this. The results provide evidence that the emotional structure difference and their processing are relevant only in work-related decisions and not in investment-related decisions. Chi-square tests for the difference of the coefficients provide consistent results. The emotional structure similarity significantly differs in its effect on decision outcome of work decisions compared to investment decisions $\left(\chi^{2}(1,16)=5.89, p=0.015\right.$ and $\chi^{2}(1,16)$ $=3.61, p=0.057$ for AvgFixation and FirstFixation, respectively). Also, the effect of the interaction term, of emotional structure and processing, significantly differs between investment decisions and work decisions $\left(\chi^{2}(1,16)=11.12, p=0.015\right.$ and $\chi^{2}(1,16)=8.43, p=0.003$ for AvgFixation and FirstFixation, respectively). In other words, the level to which the decision is affect-related rather than competence-related appears to determine whether SNS-emotion-triggered emotions yield changes in decision outcome.

\section{SUMMARY AND DISCUSSION}

In this research, we have analyzed the emotional processes that may emerge in non-SNS sites, due to emotions associated with SNS sites. We find evidence that positive contagion effects coming from photos with positive emotional gestures may be moderated by such photos' potential to trigger SNS emotions. Our findings show that due to SNS emotions, the propensities to work for or invest in a company represented by a website is reduced.

As such, our findings show that visual elements that may typically be considered as positive may also have negative effects. Specifically, we show evidence that while positive emotional gestures are typically considered to facilitate a favorable reaction, this effect may be moderated by emotions related to social networks experience.

Taken together, the results of our studies have shown evidence that the emotional structure of individuals viewing a webpage that includes positively posed photos, resembles their emotional structure after viewing an SNS. We further find that the higher the similarity in emotional structure established, and the more the photos are processed, the lower the favorable contagion effect of positive gestures in the photos. Finally, the negative emotions associated with social network perceptions are correlated with the level to which positive contagion effects are mitigated.

\section{Implications for Research}

These results have many implications for both researchers and practitioners. For research, the findings of this study facilitate a better understanding of the ramifications of SNS. Information Systems research is increasingly interested in the effects of SNS, and many studies have dealt with various direct effects they may have on individuals. While there is evidence of positive effects that come from the ability to self-express and obtain help (Tamir \& Mitchell, 2012; Wang, 2013), negative emotions are largely associated with passive consumption (e.g., De Vries \& Kühne 2015; Verduyn et al. 2015). The current research improves our understanding of how those negative emotions propagate to affect behavior in other online activities. As such, we propose a promising link between social networks and other online behaviors. Namely, since social networks are highly related to emotional content, social network experience manifests emotions that one triggered in other online contexts affect behavior. We believe that our approach of relating to theories on emotions and actions (e.g., Ellsworth \& Scherer 2003; Frijda, 2017; Scherer, 2005; Strack \& Deutsch, 2004) provides a promising venue for researchers interested in analyzing the effects of social networks experience on other online behaviors. We further believe that our findings about the relevance of emotional structure similarity, and the different effects of contagion and cognitive emotion can prove useful in research focusing on the analysis of emotional processes online. 


\section{Implications for Practice}

For practitioners, this research can help facilitate the better design of online environments. We show that visual elements that may trigger emotions related to social networks may have detrimental effects. As such, designers may wish to mitigate their use of visual elements commonly found in social networks, especially if their users are also SNS users. In that case, the site may avoid including social networks triggering design elements in their websites. For example, companies that are interested in recruiting young individuals in congested areas may prefer not to include photos of their management team taken in outdoor areas. On the other hand, companies aiming for attracting investors from the older and wealthier social segments would benefit more from including such elements through emotional contagion. System designers may utilize advancement in cloud computing to better analyze their userbase, their demographics, and contexts of web interaction (Vahdat-Nejad et al., 2018; Psannis et al., 2018) and accordingly achieve efficient interface design with low computational complexity. Additionally, even if organizations wish to integrate some social functionalities in their sites in order to exploit potential benefits (Di Gangi \& Wasko, 2016; Díaz-Díaz \& Pérez-González, 2016), they may want to carefully consider which interface to include to support this. For example, such organizations may wish not to include profile pictures so that the previous SNS emotions would not be triggered in their websites.

Further, the results of this study may have more broad implications for practitioners, namely, that in general, it would be useful to consider the level to which their online environment is similar to other online environments, and thus may trigger emotions related to other online experiences. For example, it is possible that design elements commonly found in sites aimed at community support and positive causes can help trigger positive emotions in other sites. Another example is the "act" button commonly found in moral activities related sites may raise positive emotions. It is also possible that since written reviews are often with emotional experiences (Jing et al., 2018), that the inclusion of a freeform review interface may raise emotional triggers based on past experiences in reading reviews.

\section{Future Research Directions}

This study can facilitate many directions for future research. Related to the previous paragraph, it would be interesting to see how emotions are triggered in different platforms due to their visual similarity to other common platforms. We have analyzed visual elements commonly associated with social network sites, but analysis of other platforms may be similarly suggested. For example, knowledge community sites, such as Wikipedia and Stack Overflow, may trigger positive emotions due to their concentration on content related to knowledge sharing, which is not expected to be negative. Future research can examine whether borrowing design elements from such sites can prove beneficial. It is also possible to explore how some emerging specialized social networks, such as multimedia social networks (Zhang et al., 2017), may have special design elements and trigger unique emotional experiences. Another possible direction for future research is to analyze possible differences in emotional processes that take place based on user characteristics such as cultural differences, and design elements that are associated with specific regions (e.g., western vs. eastern).

Finally, a promising avenue for future research can be with respect to other effects of SNS-related emotions. While we have shown effects on interaction decisions, other effects may be analyzed. For example, future research may analyze how SNS emotion may affect the propensity to adopt or interact with new technological artifacts.

Overall, this research takes a step in advancing our understanding of the possible effects of SNS in online behavior and on the possible effects of interface design on emotions. 


\section{REFERENCES}

Aggleton, J. P., Vann, S. D., Denby, C., Dix, S., Mayes, A. R., Roberts, N., \& Yonelinas, A. P. (2005). Sparing of the familiarity component of recognition memory in a patient with hippocampal pathology. Neuropsychologia, 43(12), 1810-1823. doi:10.1016/j.neuropsychologia.2005.01.019 PMID:16154457

Apaolaza, V., Hartmann, P., Medina, E., Barrutia, J. M., \& Echebarria, C. (2013). The relationship between socializing on the Spanish online networking site Tuenti and teenagers' subjective well-being: The roles of self-esteem and loneliness. Computers in Human Behavior, 29(4), 1282-1289. doi:10.1016/j.chb.2013.01.002

Appel, H., Gerlach, A. L., \& Crusius, J. (2016). The interplay between Facebook use, social comparison, envy, and depression. Current Opinion in Psychology, 9, 44-49. doi:10.1016/j.copsyc.2015.10.006

Argyle, M. (2001). The psychology of happiness. Taylor \& Francis.

Arnold, M. B. (1960). Emotion and personality. Columbia University Press.

Ashforth, B. E., Harrison, S. H., \& Corley, K. G. (2008). Identification in organizations: An examination of four fundamental questions. Journal of Management, 34(3), 325-374. doi:10.1177/0149206308316059

Barger, P. B., \& Grandey, A. A. (2006). Service with a smile and encounter satisfaction: Emotional contagion and appraisal mechanisms. Academy of Management Journal, 49(6), 1229-1238. doi:10.5465/amj.2006.23478695

Beaudry, A., \& Pinsonneault, A. (2010). The other side of acceptance: Studying the direct and indirect effects of emotions on information technology use. Management Information Systems Quarterly, 34(4), 689-710. doi: $10.2307 / 25750701$

Bond, R. M., Fariss, C. J., Jones, J. J., Kramer, A. D., Marlow, C., Settle, J. E., \& Fowler, J. H. (2012). A 61-million-person experiment in social influence and political mobilization. Nature, 489(7415), 295-298. doi:10.1038/nature11421 PMID:22972300

Boughzala, I. (2016). Social media and value creation: Exploring the perception of Generation Y toward corporate social networking applications use. Journal of Organizational and End User Computing, 28(2), 107-123. doi:10.4018/JOEUC.2016040107

Brady, W. J., Wills, J. A., Jost, J. T., Tucker, J. A., \& Van Bavel, J. J. (2017). Emotion shapes the diffusion of moralized content in social networks. Proceedings of the National Academy of Sciences of the United States of America, 114(28), 7313-7318. doi:10.1073/pnas.1618923114 PMID:28652356

Bugental, D. B. (1986). Unmasking the "polite smile" situational and personal determinants of managed affect in adult-child interaction. Personality and Social Psychology Bulletin, 12(1), 7-16. doi:10.1177/0146167286121001

Bushee, B. J., \& Miller, G. S. (2012). Investor relations, firm visibility, and investor following. The Accounting Review, 87(3), 867-897. doi:10.2308/accr-10211

Caparrelli, F., D’Arcangelis, A. M., \& Cassuto, A. (2004). Herding in the Italian stock market: A case of behavioral finance. Journal of Behavioral Finance, 5(4), 222-230. doi:10.1207/s15427579jpfm0504_5

Carlson, J. R., Zivnuska, S., Harris, R. B., Harris, K. J., \& Carlson, D. S. (2016). Social media use in the workplace: A study of dual effects. Journal of Organizational and End User Computing, 28(1), 15-31. doi:10.4018/JOEUC.2016010102

Cheikh-Ammar, M., \& Barki, H. (2016). The influence of social presence, social exchange and feedback features on SNS continuous use: The Facebook context. Journal of Organizational and End User Computing, 28(2), 33-52. doi:10.4018/JOEUC.2016040103

Chmiel, A., Sienkiewicz, J., Thelwall, M., Paltoglou, G., Buckley, K., Kappas, A., \& Hołyst, J. A. (2011). Collective emotions online and their influence on community life. PLoS One, 6(7), e22207. doi:10.1371/journal. pone.0022207 PMID:21818302

Cohen-Charash, Y. (2009). Episodic envy. Journal of Applied Social Psychology, 39(9), 2128-2173. doi:10.1111/ j.1559-1816.2009.00519.x 
Coviello, L., Sohn, Y., Kramer, A. D., Marlow, C., Franceschetti, M., Christakis, N. A., \& Fowler, J. H. (2014). Detecting emotional contagion in massive social networks. PLoS One, 9(3), e90315. doi:10.1371/journal. pone.0090315 PMID:24621792

Cropanzano, R., Rupp, D. E., \& Byrne, Z. S. (2003). The relationship of emotional exhaustion to work attitudes, job performance, and organizational citizenship behaviors. The Journal of Applied Psychology, 88(1), 160-169. doi:10.1037/0021-9010.88.1.160 PMID:12675403

De Vries, D. A., \& Kühne, R. (2015). Facebook and self-perception: Individual susceptibility to negative social comparison on Facebook. Personality and Individual Differences, 86, 217-221. doi:10.1016/j.paid.2015.05.029

Di Gangi, P. M., \& Wasko, M. M. (2016). Social media engagement theory: Exploring the influence of user engagement on social media usage. Journal of Organizational and End User Computing, 28(2), 53-73. doi:10.4018/JOEUC.2016040104

Díaz-Díaz, R., \& Pérez-González, D. (2016). Implementation of social media concepts for e-government: Case study of a social media tool for value co-creation and citizen participation. Journal of Organizational and End User Computing, 28(3), 104-121. doi:10.4018/JOEUC.2016070107

Diener, E., Oishi, S., \& Lucas, R. E. (2003). Personality, culture, and subjective well-being: Emotional and cognitive evaluations of life. Annual Review of Psychology, 54(1), 403-425. doi:10.1146/annurev. psych.54.101601.145056 PMID:12172000

Dimotakis, N., Scott, B. A., \& Koopman, J. (2011). An experience sampling investigation of workplace interactions, affective states, and employee well-being. Journal of Organizational Behavior, 32(4), 572-588. doi:10.1002/job.722

Ekman, P. E., \& Davidson, R. J. (1994). The nature of emotion: Fundamental questions. Oxford University Press.

Ellsworth, P. C., \& Scherer, K. R. (2003). Appraisal processes in emotion. Handbook of Affective Sciences, 572, V595.

Epstein, M. J., \& Freedman, M. (1994). Social disclosure and the individual investor. Accounting, Auditing \& Accountability Journal, 7(4), 94-109. doi:10.1108/09513579410069867

Farnia, F., Nafukho, F. M., \& Petrides, K. V. (2018). Predicting career decision-making difficulties: The role of trait emotional intelligence, positive and negative emotions. Frontiers in Psychology, 9, 1107. doi:10.3389/ fpsyg.2018.01107 PMID:30042704

Farraghe, E. J., Kleiman, R., \& Bazaz, M. S. (1994). Do investor relations make a difference? The Quarterly Review of Economics and Finance, 34(4), 403-412. doi:10.1016/1062-9769(94)90023-X

Frijda, N. H. (1986). The emotions. Cambridge University Press.

Frijda, N. H. (1987). Emotion, cognitive structure, and action tendency. Cognition and Emotion, 1(2), 115-143. doi:10.1080/02699938708408043

Frijda, N. H. (2017). The laws of emotion. Psychology Press. doi:10.4324/9781315086071

Frijda, N. H., Kuipers, P., \& ter Schure, E. (1989). Relations among emotion, appraisal, and emotional action readiness. Journal of Personality and Social Psychology, 57(2), 212-228. doi:10.1037/0022-3514.57.2.212

Goel, A. M., \& Thakor, A. V. (2005). Green with envy: Implications for corporate investment distortions. The Journal of Business, 78(6), 2255-2288. doi:10.1086/497049

Goh, K. Y., Heng, C. S., \& Lin, Z. (2013). Social media brand community and consumer behavior: Quantifying the relative impact of user-and marketer-generated content. Information Systems Research, 24(1), 88-107. doi:10.1287/isre.1120.0469

Grandey, A. A., Tam, A. P., \& Brauburger, A. L. (2002). Affective states and traits in the workplace: Diary and survey data from young workers. Motivation and Emotion, 26(1), 31-55. doi:10.1023/A:1015142124306

Gupta, A., Li, H., \& Sharda, R. (2013). Should I send this message? Understanding the impact of interruptions, social hierarchy and perceived task complexity on user performance and perceived workload. Decision Support Systems, 55(1), 135-145. doi:10.1016/j.dss.2012.12.035 
Hajcak, G., Weinberg, A., MacNamara, A., \& Foti, D. (2012). ERPs and the study of emotion. In S. J. Luck \& E. S. Kappenman (Eds.), Oxford library of psychology. The Oxford handbook of event-related potential components (pp. 441-472). Oxford University Press.

Hajli, M. N. (2014). A study of the impact of social media on consumers. International Journal of Market Research, 56(3), 387-404. doi:10.2501/IJMR-2014-025

Hardy, S. A. (2006). Identity, reasoning, and emotion: An empirical comparison of three sources of moral motivation. Motivation and Emotion, 30(3), 205-213. doi:10.1007/s11031-006-9034-9

Hatfield, E., Cacioppo, J. T., \& Rapson, R. L. (1994). Emotional contagion. Studies in Emotion and Social Interaction. Cambridge University Press.

Haythornthwaite, C. (2005). Social networks and Internet connectivity effects. Information Communication and Society, 8(2), 125-147. doi:10.1080/13691180500146185

Hockerts, K., \& Moir, L. (2004). Communicating corporate responsibility to investors: The changing role of the investor relations function. Journal of Business Ethics, 52(1), 85-98. doi:10.1023/B:BUSI.0000033109.35980.16

Hsieh, J. P. A., Rai, A., Petter, S., \& Zhang, T. (2012). Impact of user satisfaction with mandated CRM use on employee service quality, 36(4). Management Information Systems Quarterly, 36(4), 1065-1080. doi: $10.2307 / 41703498$

$\mathrm{Hu}$, Y., Manikonda, L., \& Kambhampati, S. (2014). What we Instagram: A first analysis of Instagram photo content and user types. Eighth International AAAI conference on weblogs and social media, 595-598.

Jiang, J., Wilson, C., Wang, X., Sha, W., Huang, P., Dai, Y., \& Zhao, B. Y. (2013). Understanding latent interactions in online social networks. ACM Transactions on the Web, 7(4), 1-39. doi:10.1145/2517040

Jing, X., Wang, P., \& Rayz, J. M. (2018). Discovering attribute-specific features from online reviews: What is the gap between automated tools and human cognition? International Journal of Software Science and Computational Intelligence, 10(2), 1-24. doi:10.4018/IJSSCI.2018040101

Judd, C. M., James-Hawkins, L., Yzerbyt, V., \& Kashima, Y. (2005). Fundamental dimensions of social judgment: Understanding the relations between judgments of competence and warmth. Journal of Personality and Social Psychology, 89(6), 899-913. doi:10.1037/0022-3514.89.6.899 PMID:16393023

Khodakarami, F., \& Chan, Y. E. (2014). Exploring the role of customer relationship management (CRM) systems in customer knowledge creation. Information \& Management, 51(1), 27-42. doi:10.1016/j.im.2013.09.001

Kim, Y. H., Kim, D. J., \& Wachter, K. (2013). A study of mobile user engagement (MoEN): Engagement motivations, perceived value, satisfaction, and continued engagement intention. Decision Support Systems, 56, 361-370. doi:10.1016/j.dss.2013.07.002

Koch, H., Gonzalez, E., \& Leidner, D. (2012). Bridging the work/social divide: The emotional response to organizational social networking sites. European Journal of Information Systems, 21(6), 699-717. doi:10.1057/ ejis.2012.18

Krasnova, H., Widjaja, T., Buxmann, P., Wenninger, H., \& Benbasat, I. (2015). Research note: Why following friends can hurt you: an exploratory investigation of the effects of envy on social networking sites among collegeage users. Information Systems Research, 26(3), 585-605. doi:10.1287/isre.2015.0588

Kross, E., Verduyn, P., Demiralp, E., Park, J., Lee, D. S., Lin, N., Shablack, H., Jonides, J., \& Ybarra, O. (2013). Facebook use predicts declines in subjective well-being in young adults. PLoS One, 8(8), e69841. doi:10.1371/ journal.pone.0069841 PMID:23967061

Labrague, L. J. (2014). Facebook use and adolescents' emotional states of depression, anxiety, and stress. Health Science Journal, 8(1), 80-89.

Lazarus, R. S. (1982). Thoughts on the relations between emotion and cognition. The American Psychologist, 37(9), 1019-1024. doi:10.1037/0003-066X.37.9.1019

LeDoux, J. (2003). The emotional brain, fear, and the amygdala. Cellular and Molecular Neurobiology, 23(4-5), 727-738. doi:10.1023/A:1025048802629 PMID:14514027 
Lee, G., Lee, J., \& Kwon, S. (2011). Use of social-networking sites and subjective well-being: A study in South Korea. Cyberpsychology, Behavior, and Social Networking, 14(3), 151-155. doi:10.1089/cyber.2009.0382 PMID:20649450

Lee, K. T., Noh, M. J., \& Koo, D. M. (2013). Lonely people are no longer lonely on social networking sites: The mediating role of self-disclosure and social support. Cyberpsychology, Behavior, and Social Networking, 16(6), 413-418. doi:10.1089/cyber.2012.0553 PMID:23621716

Lee-Won, R. J., Shim, M., Joo, Y. K., \& Park, S. G. (2014). Who puts the best "face" forward on Facebook? Positive self-presentation in online social networking and the role of self-consciousness, actual-to-total Friends ratio, and culture. Computers in Human Behavior, 39, 413-423. doi:10.1016/j.chb.2014.08.007

Lin, W. Y., Chen, P. J., \& Chen, S. S. (2011). Stock characteristics and herding in financial analyst recommendations. Applied Financial Economics, 21(5), 317-331. doi:10.1080/09603107.2010.528367

Lister, M. (2018). 40 essential social media marketing statistics for 2018. https://www.wordstream.com/blog/ ws/2017/01/05/social-media-marketing-statistics

Liu, Q. B., \& Karahanna, E. (2017). The dark side of reviews: The swaying effects of online product reviews on attribute preference construction. Management Information Systems Quarterly, 41(2), 427-448. doi:10.25300/ MISQ/2017/41.2.05

Malik, A., Dhir, A., \& Nieminen, M. (2016). Uses and gratifications of digital photo sharing on Facebook. Telematics and Informatics, 33(1), 129-138. doi:10.1016/j.tele.2015.06.009

Marino, K. E. (1996). Developing consensus on firm competencies and capabilities. The Academy of Management Perspectives, 10(3), 40-51. doi:10.5465/ame.1996.9704111473

Matook, S., Cummings, J., \& Bala, H. (2015). Are you feeling lonely? The impact of relationship characteristics and online social network features on loneliness. Journal of Management Information Systems, 31(4), 278-310. doi:10.1080/07421222.2014.1001282

Matthews, G., \& Deary, I. J. (1998). Personality traits. Cambridge University Press.

McHugo, G. J., Lanzetta, J. T., Sullivan, D. G., Masters, R. D., \& Englis, B. G. (1985). Emotional reactions to a political leader's expressive display. Journal of Personality and Social Psychology, 49(6), 1513-1529. doi:10.1037/0022-3514.49.6.1513

Mueser, K. T., Grau, B. W., Sussman, S., \& Rosen, A. J. (1984). You're only as pretty as you feel: Facial expression as a determinant of physical attractiveness. Journal of Personality and Social Psychology, 46(2), 469-478. doi:10.1037/0022-3514.46.2.469

Ollier-Malaterre, A., Rothbard, N. P., \& Berg, J. M. (2013). When worlds collide in cyberspace: How boundary work in online social networks impacts professional relationships. Academy of Management Review, 38(4), 645-669. doi:10.5465/amr.2011.0235

Pantic, I., Damjanovic, A., Todorovic, J., Topalovic, D., Bojovic-Jovic, D., Ristic, S., \& Pantic, S. (2012). Association between online social networking and depression in high school students: Behavioral physiology viewpoint. Psychiatria Danubina, 24(1), 90-93. PMID:22447092

Papacharissi, Z. (Ed.). (2010). A networked self: Identity, community, and culture on social network sites. Routledge. doi: $10.4324 / 9780203876527$

Partala, T., \& Saari, T. (2015). Understanding the most influential user experiences in successful and unsuccessful technology adoptions. Computers in Human Behavior, 53, 381-395. doi:10.1016/j.chb.2015.07.012

Paul, J. A., Baker, H. M., \& Cochran, J. D. (2012). Effect of online social networking on student academic performance. Computers in Human Behavior, 28(6), 2117-2127. doi:10.1016/j.chb.2012.06.016

Philippot, P., Schaefer, A., \& Herbette, G. (2003). Consequences of specific processing of emotional information: Impact of general versus specific autobiographical memory priming on emotion elicitation. Emotion (Washington, D.C.), 3(3), 270-283. doi:10.1037/1528-3542.3.3.270 PMID:14498796

Psannis, K. E., Stergiou, C., \& Gupta, B. B. (2018). Advanced media-based smart big data on intelligent cloud systems. IEEE Transactions on Sustainable Computing, 4(1), 77-87. doi:10.1109/TSUSC.2018.2817043 
Pugh, S. D. (2001). Service with a smile: Emotional contagion in the service encounter. Academy of Management Journal, 44(5), 1018-1027.

Qiu, L., Lin, H., Leung, A. K., \& Tov, W. (2012). Putting their best foot forward: Emotional disclosure on Facebook. Cyberpsychology, Behavior, and Social Networking, 15(10), 569-572. doi:10.1089/cyber.2012.0200 PMID:22924675

Rainie, L., Brenner, J., \& Purcell, K. (2012). Photos and videos as social currency online. Pew Internet \& American Life Project.

Rolls, E. T. (1999). The brain and emotion. Oxford University Press.

Roseman, I. J., Wiest, C., \& Swartz, T. S. (1994). Phenomenology, behaviors, and goals differentiate discrete emotions. Journal of Personality and Social Psychology, 67(2), 206-221. doi:10.1037/0022-3514.67.2.206

Rosin, H. M., \& Korabik, K. (1991). Workplace variables, affective responses, and intention to leave among women managers. Journal of Occupational Psychology, 64(4), 317-330. doi:10.1111/j.2044-8325.1991.tb00563.x

Rugg, M. D., \& Curran, T. (2007). Event-related potentials and recognition memory. Trends in Cognitive Sciences, 11(6), 251-257. doi:10.1016/j.tics.2007.04.004 PMID:17481940

Scherer, K. R. (2004). Ways to study the nature and frequency of our daily emotions: Reply to the commentaries on "Emotions in everyday life.". Social Sciences Information. Information Sur les Sciences Sociales, 43(4), 667-689. doi:10.1177/0539018404047713

Scherer, K. R. (2005). What are emotions? And how can they be measured? Social Sciences Information. Information Sur les Sciences Sociales, 44(4), 695-729. doi:10.1177/0539018405058216

Selfhout, M. H., Branje, S. J., Delsing, M., ter Bogt, T. F., \& Meeus, W. H. (2009). Different types of Internet use, depression, and social anxiety: The role of perceived friendship quality. Journal of Adolescence, 32(4), 819-833. doi:10.1016/j.adolescence.2008.10.011 PMID:19027940

Shaw, A. M., Timpano, K. R., Tran, T. B., \& Joormann, J. (2015). Correlates of Facebook usage patterns: The relationship between passive Facebook use, social anxiety symptoms, and brooding. Computers in Human Behavior, 48, 575-580. doi:10.1016/j.chb.2015.02.003

Sheets-Johnstone, M. (1999). Emotion and movement. A beginning empirical-phenomenological analysis of their relationship. Journal of Consciousness Studies, 6(11-12), 259-277.

Sheldon, P., \& Bryant, K. (2016). Instagram: Motives for its use and relationship to narcissism and contextual age. Computers in Human Behavior, 58, 89-97. doi:10.1016/j.chb.2015.12.059

Shepherd, D. A., Wiklund, J., \& Haynie, J. M. (2009). Moving forward: Balancing the financial and emotional costs of business failure. Journal of Business Venturing, 24(2), 134-148. doi:10.1016/j.jbusvent.2007.10.002

Smith, R. H., \& Kim, S. H. (2007). Comprehending envy. Psychological Bulletin, 133(1), 46-64. doi:10.1037/00332909.133.1.46 PMID:17201570

Smith, R. H., Parrott, W. G., Diener, E. F., Hoyle, R. H., \& Kim, S. H. (1999). Dispositional envy. Personality and Social Psychology Bulletin, 25(8), 1007-1020. doi:10.1177/01461672992511008

Spierings, N., \& Jacobs, K. (2014). Getting personal? The impact of social media on preferential voting. Political Behavior, 36(1), 215-234. doi:10.1007/s11109-013-9228-2

Steers, M. L. N., Wickham, R. E., \& Acitelli, L. K. (2014). Seeing everyone else's highlight reels: How Facebook usage is linked to depressive symptoms. Journal of Social and Clinical Psychology, 33(8), 701-731. doi:10.1521/ jscp.2014.33.8.701

Strack, F., \& Deutsch, R. (2004). Reflective and impulsive determinants of social behavior. Personality and Social Psychology Review, 8(3), 220-247. doi:10.1207/s15327957pspr0803_1 PMID:15454347

Straub, E. T. (2009). Understanding technology adoption: Theory and future directions for informal learning. Review of Educational Research, 79(2), 625-649. doi:10.3102/0034654308325896

Susskind, J. M., Lee, D. H., Cusi, A., Feiman, R., Grabski, W., \& Anderson, A. K. (2008). Expressing fear enhances sensory acquisition. Nature Neuroscience, 11(7), 843-850. doi:10.1038/nn.2138 PMID:18552843 
Sutton, R. I. (1991). Maintaining norms about expressed emotions: The case of bill collectors. Administrative Science Quarterly, 36(2), 245-268. doi:10.2307/2393355

Tamir, D. I., \& Mitchell, J. P. (2012). Disclosing information about the self is intrinsically rewarding. Proceedings of the National Academy of Sciences of the United States of America, 109(21), 8038-8043. doi:10.1073/ pnas.1202129109 PMID:22566617

Tandoc, E. C. Jr, Ferrucci, P., \& Duffy, M. (2015). Facebook use, envy, and depression among college students: Is Facebooking depressing? Computers in Human Behavior, 43, 139-146. doi:10.1016/j.chb.2014.10.053

Tsai, W. C., \& Huang, Y. M. (2002). Mechanisms linking employee affective delivery and customer behavioral intentions. The Journal of Applied Psychology, 87(5), 1001-1008. doi:10.1037/0021-9010.87.5.1001 PMID:12395825

Turel, O. (2015). Quitting the use of a habituated hedonic information system: A theoretical model and empirical examination of Facebook users. European Journal of Information Systems, 24(4), 431-446. doi:10.1057/ ejis.2014.19

Turel, O., \& Serenko, A. (2012). The benefits and dangers of enjoyment with social networking websites. European Journal of Information Systems, 21(5), 512-528. doi:10.1057/ejis.2012.1

Vahdat-Nejad, H., Eilaki, S. O., \& Izadpanah, S. (2018). Towards a better understanding of ubiquitous cloud computing. International Journal of Cloud Applications and Computing, 8(1), 1-20. doi:10.4018/ IJCAC.2018010101

Valenzuela, S., Park, N., \& Kee, K. F. (2009). Is there social capital in a social network site? Facebook use and college students' life satisfaction, trust, and participation. Journal of Computer-Mediated Communication, 14(4), 875-901. doi:10.1111/j.1083-6101.2009.01474.x

Venkatesh, V., \& Bala, H. (2008). Technology acceptance model 3 and a research agenda on interventions. Decision Sciences, 39(2), 273-315. doi:10.1111/j.1540-5915.2008.00192.x

Verduyn, P., Lee, D. S., Park, J., Shablack, H., Orvell, A., Bayer, J., Ybarra, O., Jonides, J., \& Kross, E. (2015). Passive Facebook usage undermines affective well-being: Experimental and longitudinal evidence. Journal of Experimental Psychology. General, 144(2), 480-488. doi:10.1037/xge0000057 PMID:25706656

Wang, H., Prendinger, H., \& Igarashi, T. (2004). Communicating emotions in online chat using physiological sensors and animated text. CHI'O4 Extended Abstracts on Human Factors in Computing Systems, 1171-1174.

Wang, S. S. (2013). "I share, therefore I am": Personality traits, life satisfaction, and Facebook checkins. Cyberpsychology, Behavior, and Social Networking, 16(12), 870-877. doi:10.1089/cyber.2012.0395 PMID:23992473

Watkins, E., Moberly, N. J., \& Moulds, M. L. (2008). Processing mode causally influences emotional reactivity: Distinct effects of abstract versus concrete construal on emotional response. Emotion (Washington, D.C.), 8(3), 364-378. doi:10.1037/1528-3542.8.3.364 PMID:18540752

Whiting, A., \& Williams, D. (2013). Why people use social media: A uses and gratifications approach. Qualitative Market Research, 16(4), 362-369. doi:10.1108/QMR-06-2013-0041

Xie, C., Bagozzi, R. P., \& Grønhaug, K. (2015). The role of moral emotions and individual differences in consumer responses to corporate green and non-green actions. Journal of the Academy of Marketing Science, 43(3), 333-356. doi:10.1007/s11747-014-0394-5

Ybarra, O., Chan, E., \& Park, D. (2001). Young and old adults' concerns about morality and competence. Motivation and Emotion, 25(2), 85-100. doi:10.1023/A:1010633908298

Yonelinas, A. P. (2001). Components of episodic memory: The contribution of recollection and familiarity. Philosophical Transactions of the Royal Society of London. Series B, Biological Sciences, 356(1413), 1363-1374. doi:10.1098/rstb.2001.0939 PMID:11571028

Zhang, Z., Sun, R., Zhao, C., Wang, J., Chang, C. K., \& Gupta, B. B. (2017). CyVOD: A novel trinity multimedia social network scheme. Multimedia Tools and Applications, 76(18), 18513-18529. doi:10.1007/s11042-016$4162-\mathrm{z}$ 


\section{ENDNOTES}

Or possible herding behaviors, which may be considered as a sign of emotions associated with trading in general (Lin et al., 2011; Caparrelli et al. 2004).

2 The order of viewing the non-SNS triggering site vs the SNS triggering site was counterbalanced between subject.

3 The comparison measure is the vector distance between the two. That is, the square root of the summed square distance with respect to the agreement with each of the 36 emotion words. 


\section{APPENDIX}

\section{Table 6. Factor loadings}

\begin{tabular}{|c|c|c|c|c|}
\hline & $\begin{array}{l}\text { Propensity for } \\
\text { investment }\end{array}$ & $\begin{array}{l}\text { Propensity for } \\
\text { working }\end{array}$ & SNAWB & Dispositional envy \\
\hline \multicolumn{5}{|c|}{ When you think about investing in this company, you feel ... } \\
\hline ... excited & 0.88 & 0.12 & -0.01 & -0.02 \\
\hline ... happy & 0.86 & 0.11 & 0.02 & 0.04 \\
\hline ... motivated & 0.95 & 0.02 & 0.01 & 0.03 \\
\hline$\ldots$ that this is something you would like to do & 0.88 & 0.09 & -0.01 & -0.03 \\
\hline \multicolumn{5}{|c|}{ When you think about yourself working for this company, you feel ... } \\
\hline ... excited & 0.17 & 0.80 & 0.00 & -0.02 \\
\hline ... happy & 0.15 & 0.83 & 0.02 & 0.04 \\
\hline ... motivated & 0.07 & 0.84 & 0.02 & -0.02 \\
\hline$\ldots$ that this is something you would like to do & 0.02 & 0.90 & -0.00 & -0.03 \\
\hline \multicolumn{5}{|c|}{ When you think about how you typically feel when using Facebook, to what extent do you feel ... } \\
\hline ... happy & 0.00 & 0.02 & 0.94 & 0.05 \\
\hline ... optimistic & -0.02 & -0.03 & 0.86 & -0.03 \\
\hline ... excited & 0.11 & 0.04 & 0.74 & 0.08 \\
\hline$\ldots$ good about myself & -0.06 & 0.01 & 0.86 & -0.11 \\
\hline $\begin{array}{l}\text { The bitter truth is that I generally feel inferior to } \\
\text { others. }\end{array}$ & -0.05 & -0.01 & -0.00 & 0.92 \\
\hline Feelings of envy constantly torment me. & 0.15 & -0.08 & 0.05 & 0.68 \\
\hline I am troubled by feelings of inadequacy. & -0.07 & 0.06 & -0.06 & 0.91 \\
\hline
\end{tabular}


Figure 3. Example of counterbalancing between subjects. The same team members were depicted in different design settings between subjects-triggering an SNS emotional structure, and a non-SNS emotional structure.
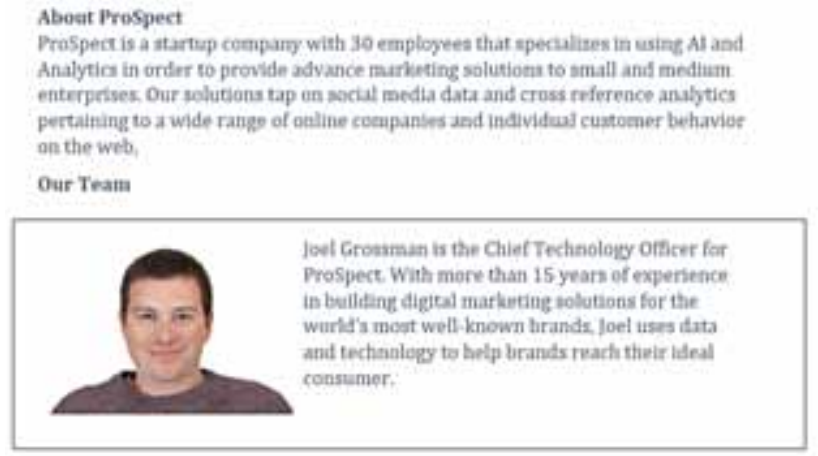

Michael Glefke is ProSpect's Managing Directot. Michael aversees business eperations and Client services for ProSpett offices. Moat recently, Michael served as VP. Group Account Dirncter. Nror to joiniang Prospect is $201 \mathrm{~h}$ he ran sales and cliest services at Exholory. A digtal marketiag industry viteran, he has ever 10 yeara of experience working with leating branda in drwine thes business forwant.
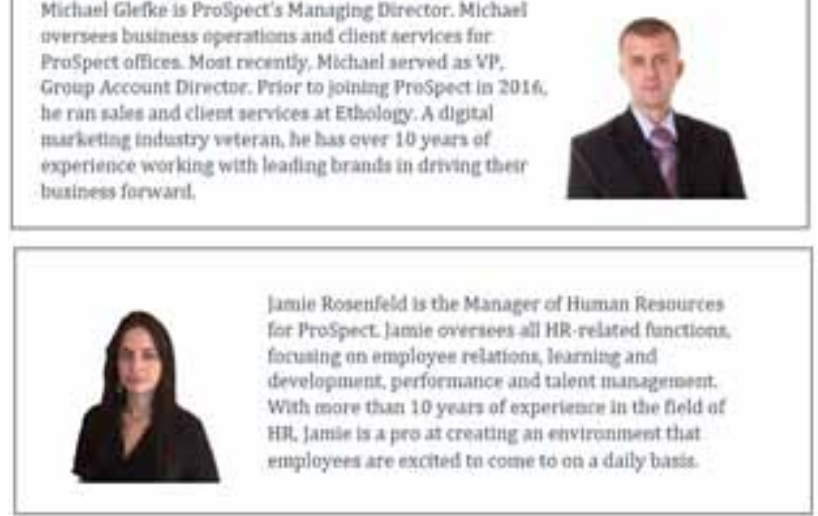

Eran Rubin $(P h D)$ is an Associate Professor of Management Information Systems at California State University Fresno. His research interests include trust in IS, decision support systems, systems design, and financial impacts of IS. Dr. Rubin has published in various journals including Marketing Science, Information \& Management, the Journal of Business Finance and Accounting, Electronic Commerce Research and Applications, and Requirements Engineering. He received his Ph.D. in Management Information Systems from the University of British Columbia.

Frederik Beuk $(P h D)$ is an Associate Professor of marketing at the Fisher Institute for Professional Selling at the University of Akron. He received his Ph.D. from the University of Illinois at Chicago. Dr. Beuk's research has been published among others in the Journal of Product Innovation Management, the Journal of Product and Brand Management, the Journal of Personal Selling \& Sales Management, and Creativity and Innovation Management. 